\title{
Triaxial Compression Test on Consolidated Undrained Shear Strength Characteristics of Fiber Reinforced Soil
}

\author{
T.S. Hou, J.L. Liu, Y.S. Luo, Y.X. Cui
}

\begin{abstract}
This study aims to experimentally analyze the effect of fiber length and fiber content on shear strength and deformation properties of fiber reinforced soil by consolidated-undrained triaxial shear tests. The best mechanical properties are presented by the samples with $1.0 \%$ fiber content and $3.09 \mathrm{~cm}$ fiber length. The stress-strain relationship of fiber reinforced soil is strain hardening. The change laws of pore water pressure with the increasing of axial strain are affected by both confining pressure and the void ratio. The effective stress paths of fiber reinforced soil move to the left of the $p^{\prime}-q$ surface with the increase of fiber content, and the fiber length has no significant effect on effective stress paths. Reinforcement effect mainly improves the cohesion of soil samples, and three distribution patterns of flexible fibers in soil are proposed. The failure mode of saturated cotton fiber reinforced soil is bulging failure, radial deformation of soil is obviously restrained by fiber reinforcement.
\end{abstract}

Keywords: consolidated undrained shear characteristics, fiber content, fiber length, reinforced soil, stress-strain characteristics, shear strength.

\section{Introduction}

A composite geotextile made from a random and uniform mix of fiber materials into soil is called fiber reinforced soil. As for the technology of soil improvement, lime soil, cement soil, EPS (expanded polystyrene) particles light weight soil (Hou \& Xu, 2009; Hou \& Xu, 2010) and so on can be regarded as artificial composite soil. However, as the global community is turning to a more sustainable way of development, it encourages the stabilization technology that can replace or minimize the use of traditional cement and other curing agents. In this respect, the use of fibers has been favored by many scholars. In the rural areas of Northwest China, it is still possible to see the courtyard walls and houses built from the loess with straw and other natural fiber materials in it. It can be seen that fiber reinforced soil has already been used in production practice, but the theoretical research of fiber reinforced soil is far behind the practice. The problems such as reinforcement mechanism, reinforcement effect, strength parameters and so on remain to be studied.

The fiber materials used in the study are mainly composed of natural fibers such as wheat straw (Wei et al., 2012), grass root (Wang et al., 2015), sisal (Prabakar \& Sridhar, 2002), cotton (Zhang et al., 2005) and synthetic fiber such as polypropylene (Shao et al., 2014), nylon (Estabragh et al., 2011), polyester fiber (Chaduvul et al., 2017) and so on. The study found that the fiber properties such as content, length, toughness, fineness and vertical and horizontal ratio, and soil properties such as water content, dry density, particle size distribution have an important influence on the strength of fiber reinforced soil (Chai \& Shi, 2012; Krishna Rao \& Nasr, 2012; Diambra \& Ibraim, 2015; Tang et al., 2016a; Tang et al., 2016b). The effect of fiber content and fiber length on mechanical properties of fiber reinforced fine sand is studied through the California soil bearing ratio tests and direct shear tests by Krishna Rao \& Nasr (2012). The test results show that the mechanical properties of fiber reinforced soil are optimal when the percentage of fiber mass to dry sand mass is $0.75 \%$. The tensile strength of polypropylene fiber reinforced soil is researched by Tang et al. (2016b), and the results show that the fiber reinforcement can significantly increase the peak strength of the soil, and the tensile strength increases with the increasing of fiber content and dry density, and decreases with the increasing of water content. Through the drying tests, it is found that the reinforcement of the fibers significantly reduces the cracking of the soil. Using the improved shear lag theory, the stress transfer mechanism between local fibers and soil particles is studied by Diambra \& Ibraim (2015), and the effects of geometry of the fibers and particle size of the soil on the stress distribution along the fiber direction are clarified. Fiber reinforcement can not only effectively enhance the compressive strength, shear

Tian-shun Hou, Ph.D., Associate Professor, College of Water Resources and Architectural Engineering, Northwest A\&F University, No. 23 Weihui Road, Yangling, Shaanxi, China. e-mail: houtianshunyx@ sina.com.

Jian-long Liu, M.Sc. Student, College of Water Resources and Architectural Engineering, Northwest A\&F University, No. 23 Weihui Road, Yangling, Shaanxi, China. e-mail: jianlong8903@163.com.

Ya-sheng Luo, Ph.D., Professor, College of Water Resources and Architectural Engineering, Northwest A\&F University, No. 23 Weihui Road, Yangling, Shaanxi, China. e-mail: lyas1967@nwsuaf.edu.cn.

Yi-xiang Cui, M.Sc. Student, College of Water Resources and Architectural Engineering, Northwest A\&F University, No. 23 Weihui Road, Yangling, Shaanxi, China. e-mail: 644139744@qq.com.

Submitted on December 23, 2018; Final Acceptance on February 13, 2020; Discussion open until August 31, 2020

DOI: $10.28927 /$ SR.431043 
strength, tensile strength, plasticity and toughness of the soil (Anagnostopoulos et al., 2013; Correia et al., 2015; Diab et al., 2016), but also improve the characteristics of special soils, such as expansive soil (Soltani et al., 2018), frozen soil (Zaimoglu, 2010) and so on. In the action mechanism of reinforced soil, it is found that the enhancement effect of the fiber reinforced soil depends on the interfacial force between the fibers and the soil through single fiber pull-out tests and scanning electron microscope tests by Tang et al. (2009). For the modeling analysis of fiber reinforced soil, the function of fiber distribution in reinforced sand with random fiber distribution is given by Ibraim et al. (2012). The kinematic method of limit analysis is proposed by Michalowski (2008). The constitutive model of fiber reinforced sand based on triaxial tests is established by Diambra et al. (2013).

Most of the studies are based on sand, the research on cohesive soil is still less, and theoretical research of reinforced soil is still not systematic and mature. For the saturated clay ground, the soil is fully consolidated in the existing stress system. Due to the construction needs, the undrained condition is formed by the rapid loading on the ground. The ground stability and bearing capacity should be analyzed with the consolidated-undrained strength parameters under the condition above. The pore water pressure and effective stress parameters which are for ground stability analysis can be accurately measured by consolidated-undrained triaxial tests (CU), and consolidated-undrained tests can solve the problem of long drainage test time. With cotton fibers as reinforcing material and loess as raw material, the saturated cotton fiber reinforced soil with different fiber content and fiber length is tested by consolidated-undrained tests, and the consolidated undrained shear strength, deformation and pore pressure characteristics of the soil are studied. The research achievements can propose a new understanding for the consolidated undrained strength and deformation characteristics of reinforced soil, and it can also provide theoretical support for the application of fiber reinforcement technology, such as in ground improvement, slope treatment in the loess region, and so on.

\section{Experimental Materials and Methods}

\subsection{Experimental materials}

The fibers used in the tests are made of pure cotton. The basic physical and mechanical properties are given in Table 1.

The soil used in the tests is the loess of Yangling area in Shaanxi province of China, whose grain size distribution curve is shown in Fig. 1. The optimum water content of the soil is $19.4 \%$ and the maximum dry density is $1.68 \mathrm{~g} / \mathrm{cm}^{3}$. The loess is a type of low liquid limit clay according to the plasticity chart. The other physical properties are shown in Table 2.

\subsection{Sample preparation}

The Yangling loess is air-dried and crushed into small particles, and then is passed through a $2 \mathrm{~mm}$ sieve to remove the debris and gravels. Some water is sprayed into the soil until the water content reaches the optimum water content $19.4 \%$. Then the wet soil is put into freshness protection packages for $24 \mathrm{~h}$. After that, the target fiber mass is weighed, and then water is sprayed on the fibers. By keeping the mass of water and the mass of fibers the same, we make the water content of the fibers $w_{f}=100 \%$. Based on a lot of experimental results, when $w_{f}>100 \%$, fibers and soil are difficult to mix evenly, fibers are floating on mixed soil; when $w_{f}<100 \%$, bleeding phenomenon occurs during the compaction process of the fiber and soil mixture; only

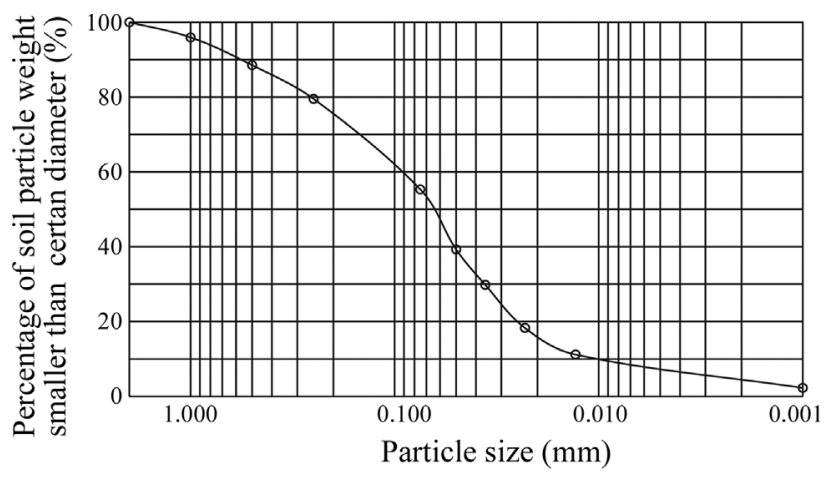

Figure 1 - Grain size distribution curve.

Table 1 - Physical and mechanical parameters of cotton fiber.

\begin{tabular}{lcccc}
\hline Density, $\rho\left(\mathrm{gcm}^{-3}\right)$ & Diameter, $D(\mathrm{~mm})$ & Elongation $(\%)$ & Tensile strength $(\mathrm{MPa})$ & Elasticity modulus $(\mathrm{MPa})$ \\
\hline 1.54 & 0.8 & 37.0 & 8.2 & 40.0 \\
\hline
\end{tabular}

Table 2 - Physical properties of Yangling loess in Shaanxi area.

\begin{tabular}{|c|c|c|c|c|c|c|c|}
\hline $\begin{array}{l}\text { Natural densi- } \\
\text { ty, } \rho\left(\mathrm{gcm}^{-3}\right)\end{array}$ & $\begin{array}{c}\text { Specific } \\
\text { gravity, } G_{s}\end{array}$ & $\begin{array}{l}\text { Natural water } \\
\text { content, } w(\%)\end{array}$ & $\begin{array}{c}\text { Plastic limit, } w_{p} \\
(\%)\end{array}$ & $\begin{array}{c}\text { Liquid } \\
\text { limit, } w_{L}(\%)\end{array}$ & $\begin{array}{l}\text { Plasticity } \\
\text { index, } I_{p}\end{array}$ & $\begin{array}{l}\text { Liquidity } \\
\text { index, } I_{L}\end{array}$ & Void ratio, $e$ \\
\hline 1.69 & 2.72 & 19.1 & 20.6 & 34.2 & 13.6 & -0.11 & 0.92 \\
\hline
\end{tabular}


when $w_{f}=100 \%$, the compaction effect of fiber reinforced soil is the best. After a while, the fibers are fully stirred with the cured soil, so that the fibers are distributed in the soil randomly and evenly. After mixing evenly, the samples are prepared for light compaction tests. The size of soil samples is $61.8 \mathrm{~mm}$ in diameter and $125 \mathrm{~mm}$ in height. The compaction work is $592.2 \mathrm{~kJ} / \mathrm{m}^{3}$, the mass of hammer in the tests is $884.92 \mathrm{~g}$, and the height of drop distance is $275 \mathrm{~mm}$. The compaction of samples is divided into three layers, and the average compaction blows for each soil layer is 31 (Hou, 2012; Hou, 2014; Hou \& Xu, 2011). In this way, the reinforced soil samples are prepared. In addition, the water content of unreinforced soil is the optimum water content $(19.4 \%)$, and the unreinforced soil samples are prepared using the same preparation methods as reinforced soil samples. After compaction, the wet density of unreinforced soil sample $\rho_{w e t}$ is $1.875 \mathrm{~g} / \mathrm{cm}^{3}$, dry density $\rho_{d}$ is $1.57 \mathrm{~g} / \mathrm{cm}^{3}$, degree of compaction $D_{c}$ is $93.47 \%$. Then the samples are saturated by the vacuum saturation method, the air-pumping time is not less than $1 \mathrm{~h}$, and the soaking time is not less than $10 \mathrm{~h}$. It is found through unconfined compression tests that the strength is optimum when the fiber content of the cotton fiber reinforced soil is $1.0 \%$ and the fiber length is $D / 2(D$ is the diameter of the sample) (Liu et al., 2018). Thus, the sample preparation scheme of fiber reinforced soil samples and the wet density of fiber reinforced soil samples in the tests are shown in Table 3.

\subsection{Experimental methods}

The consolidated undrained triaxial test $(\mathrm{CU})$ is used in the tests. The confining pressures are respectively $100 \mathrm{kPa}, 200 \mathrm{kPa}, 300 \mathrm{kPa}$ and $400 \mathrm{kPa}$, and the shear rate is $0.1660 \mathrm{~mm} / \mathrm{min}$ (shear strain rate is $0.13 \% / \mathrm{min}$ ). The tests should be ended with shear failure or $20 \%$ axial strain. The pore water pressure can be measured by sensors during the tests. The peak shear strength is chosen as the strength value. The shear strength of $15 \%$ axial strain is chosen as the strength value when there is no peak shear strength.

\section{Experimental results}

\subsection{Stress - strain - pore water pressure relation}

(1) As can be seen in Fig. 2(a) to (j), the deviator stress of fiber reinforced soil increases rapidly at the initial stage of strain, and then slowly increases until the end of the tests. The stress-strain relationship of the reinforced soil is strain hardening. The stress-strain relationship curve of fiber rein- forced soil is nonlinear, and the failure mode of the samples is bulging failure. Unreinforced soil also has the same change laws. (2) In Fig. 2(b) to (g), under the condition of $3.09 \mathrm{~cm}$ fiber length, when the confining pressure is the same, the deviator stress (when shear failure or $15 \%$ axial strain) increases first and then decreases with the increasing of the fiber content. The deviator stress is maximum when the fiber content is $1.0 \%$. For example, under the condition of $200 \mathrm{kPa}$ confining pressure and $3.09 \mathrm{~cm}$ fiber length, when the fiber content increases from 0 to $1.0 \%$, the deviator stress increases $6.6 \%$, from $334 \mathrm{kPa}$ to $356 \mathrm{kPa}$. When the fiber content increases from $1.0 \%$ to $3.0 \%$, and the deviator stress decreases $14.3 \%$, from $356 \mathrm{kPa}$ to $305 \mathrm{kPa}$. (3) In Fig. 2(c) and (h) to (j), under the condition of $1.0 \%$ fiber content, when the confining pressure is the same, the deviator stress (when shear failure or $15 \%$ axial strain) increases first and then decreases with the increasing of fiber length. $3.09 \mathrm{~cm}$ is the optimal fiber length. For example, under the condition of $200 \mathrm{kPa}$ confining pressure and $1.0 \%$ fiber content, when the fiber length increases from 0 to $3.09 \mathrm{~cm}$, the deviator stress increases $6.6 \%$, from $334 \mathrm{kPa}$ to $356 \mathrm{kPa}$. When the fiber length increases from $3.09 \mathrm{~cm}$ to $6.18 \mathrm{~cm}$, the deviator stress decreases $4.8 \%$, from $356 \mathrm{kPa}$ to $339 \mathrm{kPa}$. (4) The improvement effect of fiber in soil is better at high confining pressure. Under the optimal reinforcement conditions (1.0\% fiber content and $3.09 \mathrm{~cm}$ fiber length), the deviator stress (when shear failure or $15 \%$ axial strain) under the confining pressure of $100 \mathrm{kPa}, 200 \mathrm{kPa}, 300 \mathrm{kPa}$ and $400 \mathrm{kPa}$ increases by $3.1 \%, 6.6 \%, 17.1 \%$ and $19.5 \%$ respectively compared with the unreinforced soil. (5) In Fig. 2(a), the pore water pressure of unreinforced soil increases first and then decreases with the increasing of axial strain. In Fig. 2(b), (c) and (h), when the confining pressure is lower and the fiber content is smaller, the properties of reinforced soil are the same as those of unreinforced soil. (6) In Fig. 2(d) to $(\mathrm{g})$, under higher confining pressure and bigger fiber content, the pore water pressure increases gradually with the increasing of axial strain, then tends to be stable.

To sum up, the optimal fiber content of fiber reinforced soil is $1.0 \%$, and the optimal fiber length is $3.09 \mathrm{~cm}$. The stress-strain relationship of the reinforced soil is strain hardening. The stress-strain relationship curves of fiber reinforced soil are nonlinear, and the failure mode of the samples is bulging failure. Under lower confining pressure and lower void ratio, the mechanical properties of reinforced soil during the loading process are similar to those of unreinforced soil, and the pore water pressure increases first and then de-

Table 3 - Sample preparation scheme of reinforced soil samples.

\begin{tabular}{lcc}
\hline Fiber length, $L(\mathrm{~cm})$ & $\begin{array}{c}\text { Fiber content (mass ratio of dry fiber to dry soil), } \\
a_{f}(\%)\end{array}$ & $\begin{array}{c}\text { Wet density of reinforced soil samples, } \\
\rho_{\text {wet }}\left(\mathrm{gcm}^{-3}\right)\end{array}$ \\
\hline 3.09 & $0.5 ; 1.0 ; 1.5 ; 2.0 ; 2.5 ; 3.0$ & $1.858 ; 1.840 ; 1.826 ; 1.810 ; 1.787 ; 1.760$ \\
$1.55 ; 3.09 ; 4.64 ; 6.18$ & 1.0 & 1.840 \\
\hline
\end{tabular}


creases with increasing axial strain, which means that the interaction between fiber and soil is not obvious. Under higher confining pressure and higher void ratio, the interaction between fiber and soil is enhanced, the pore water pressure increases gradually with increasing axial strain, and then tends to be stable. The main cause of the stress-strain-pore water pressure relationship characteristics of fiber reinforced soil is shearing dilatancy or shearing shrinkage of the soil samples. In the drained tests of saturated soil, the water in the pore has sufficient time to squeeze out or breathe in, the shear dilatancy can be characterized using the macroscopic volume change. In the undrained tests of saturated soil, the wa-
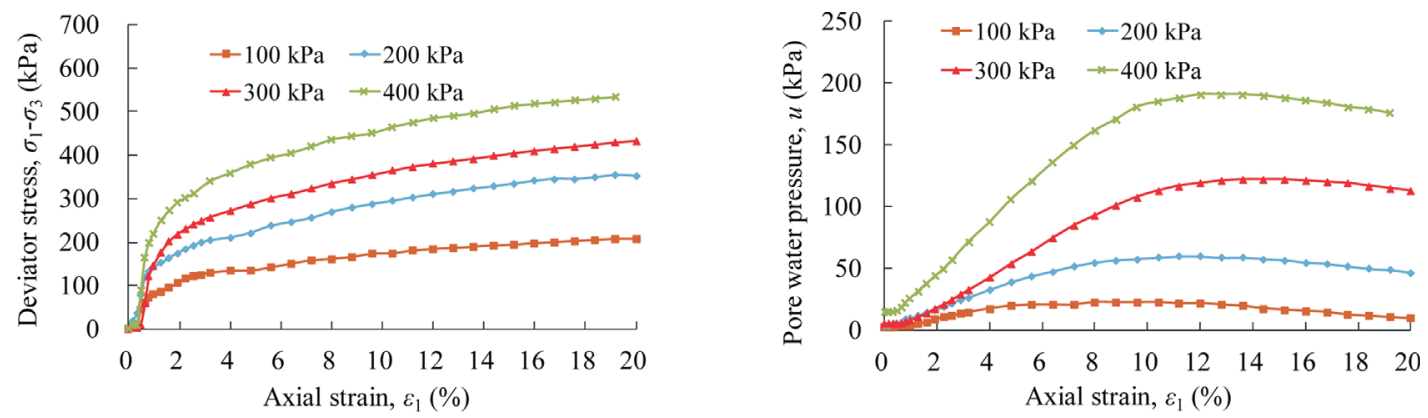

(a) Unreinforced soil
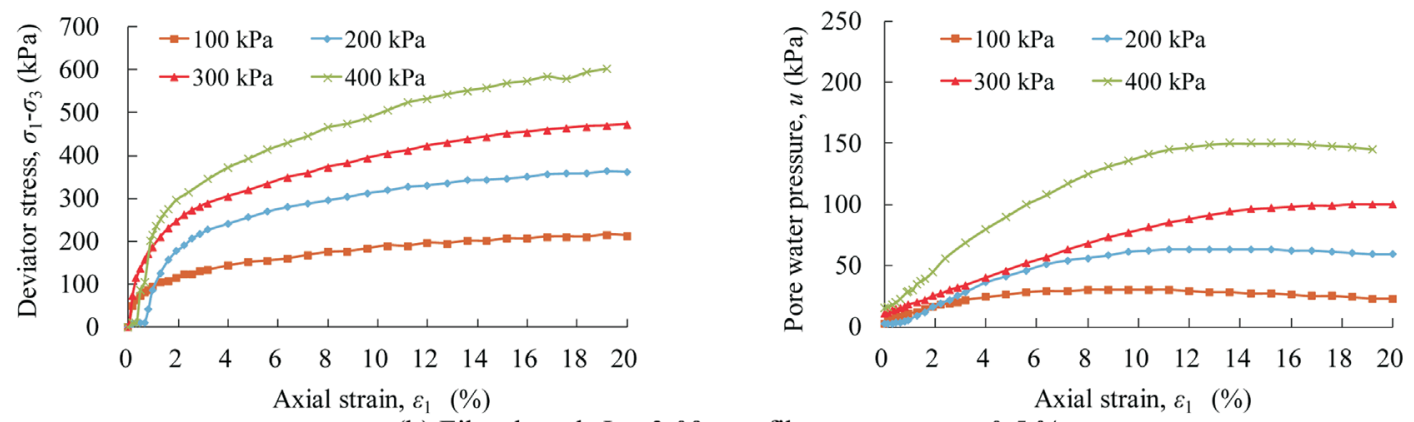

(b) Fiber length $L=3.09 \mathrm{~cm}$, fiber content $a_{f}=0.5 \%$
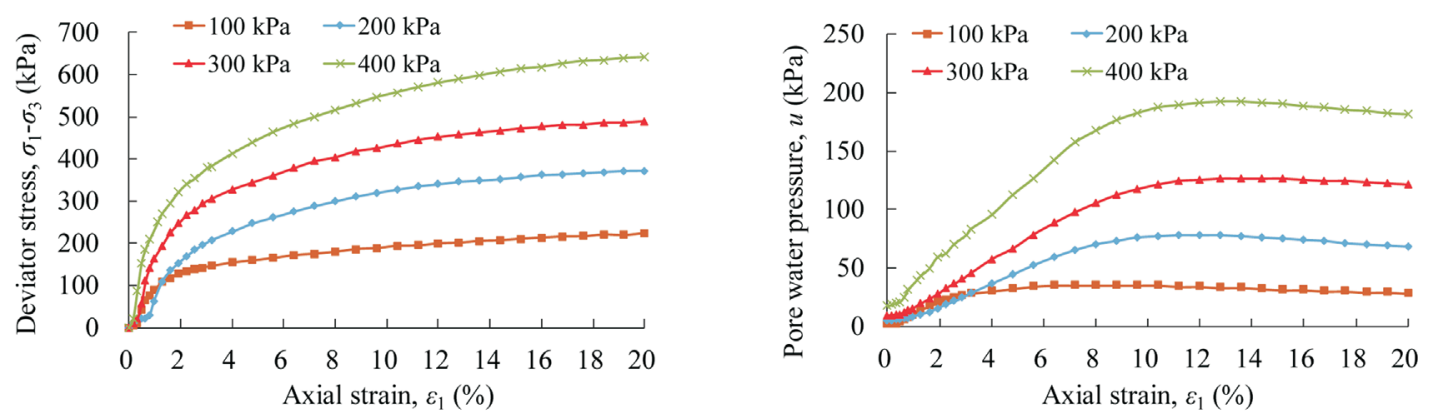

(c) Fiber length $L=3.09 \mathrm{~cm}$, fiber content $a_{f}=1.0 \%$
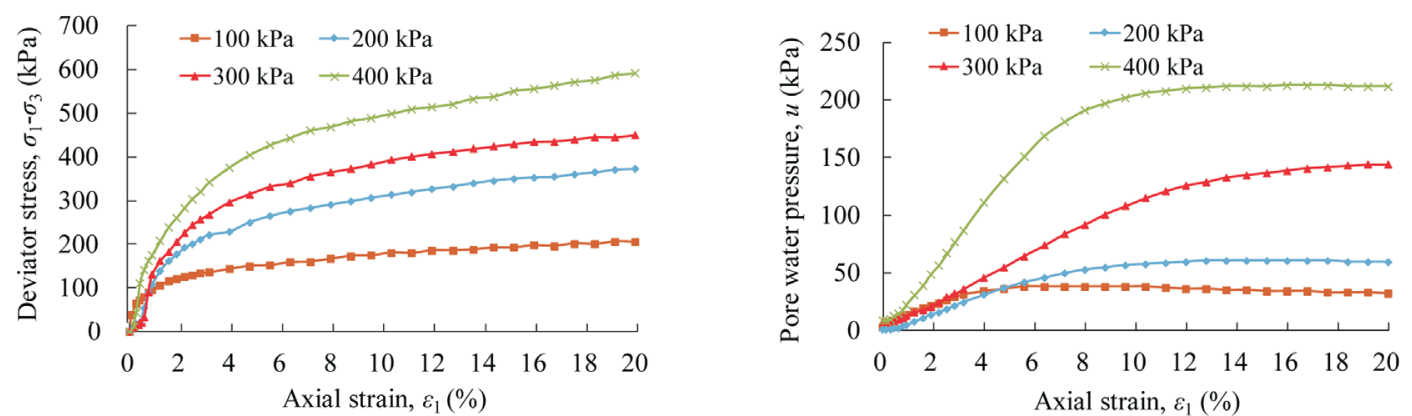

(d) Fiber length $L=3.09 \mathrm{~cm}$, fiber content $a_{f}=1.5 \%$

Figure 2 - Stress - strain - pore water pressure relation curves. 

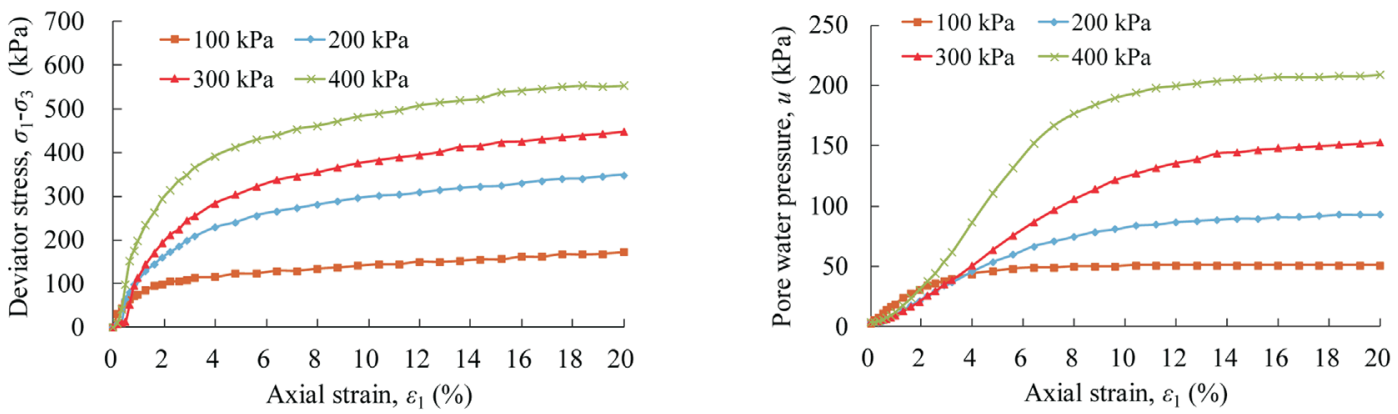

(e) Fiber length $L=3.09 \mathrm{~cm}$, fiber content $a_{f}=2.0 \%$
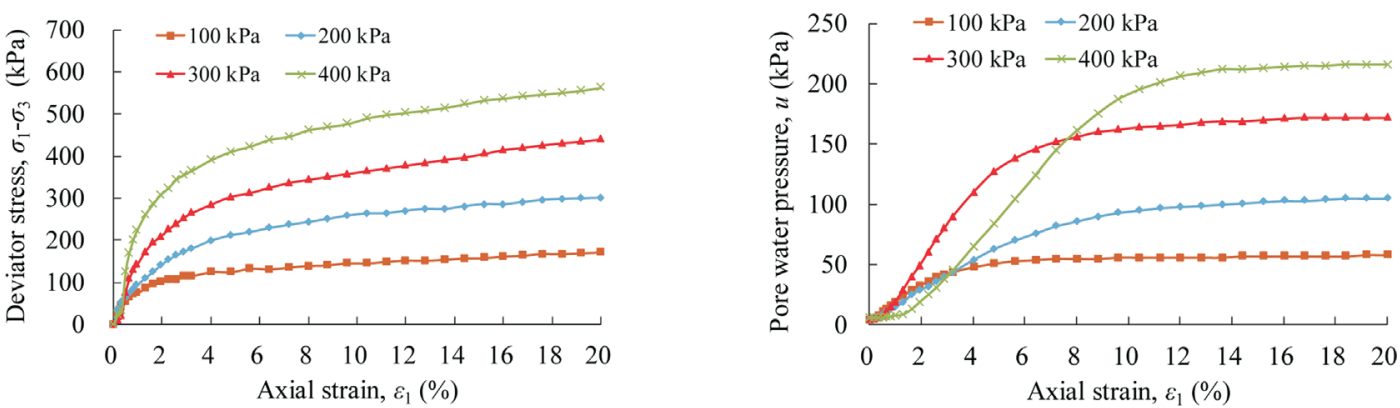

(f) Fiber length $L=3.09 \mathrm{~cm}$, fiber content $a_{f}=2.5 \%$
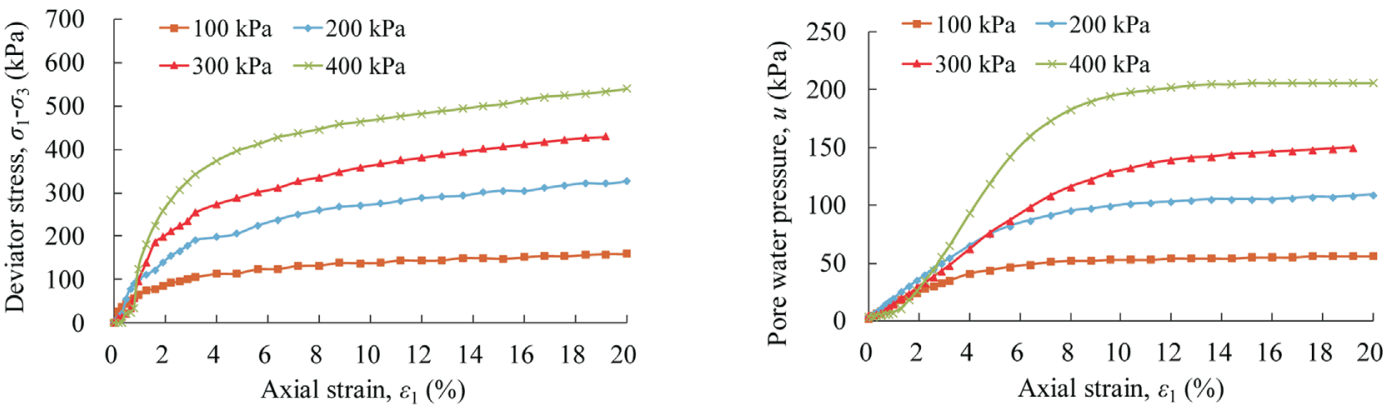

(g) Fiber length $L=3.09 \mathrm{~cm}$, fiber content $a_{f}=3.0 \%$
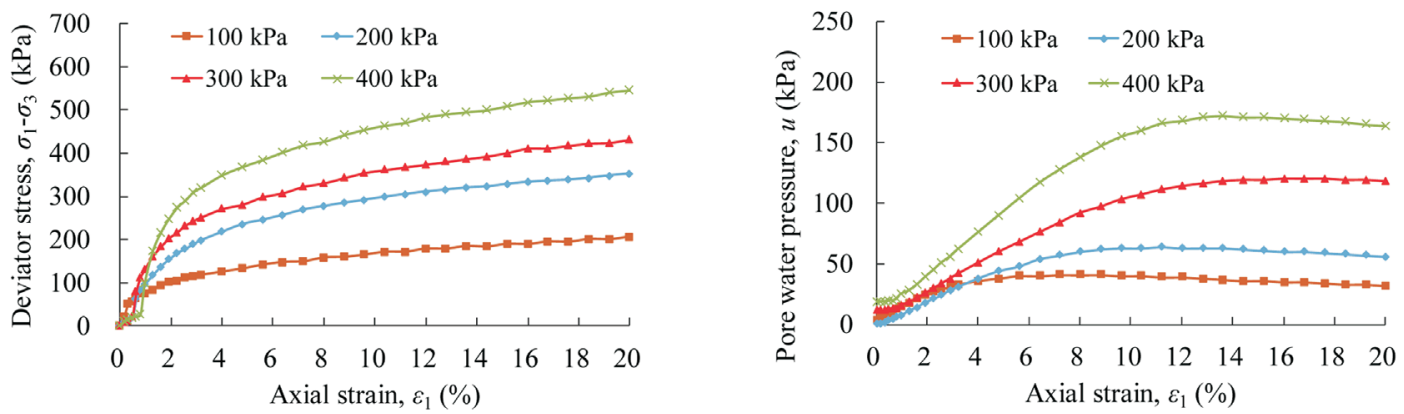

(h) Fiber content $a_{f}=1.0 \%$, fiber length $L=1.55 \mathrm{~cm}$

Figure 2 (cont.) - Stress - strain - pore water pressure relation curves.

ter in the pore cannot be squeezed out or breathe in, and the volume of saturated soil is constant during the shearing process, but the shear dilatancy still exists. Meanwhile, it is characterized as "body changing potential energy", which means the change of pore water pressure in the soil samples. When the samples have shear dilatancy tendency but the vol- ume change is restricted, the pore water pressure decreases and the effective stress on the soil particles and fibers increases. However, the pore water pressure increases and the effective stress on the soil particles and fibers decreases when the samples have shear shrinkage tendency but the volume change is restricted. 

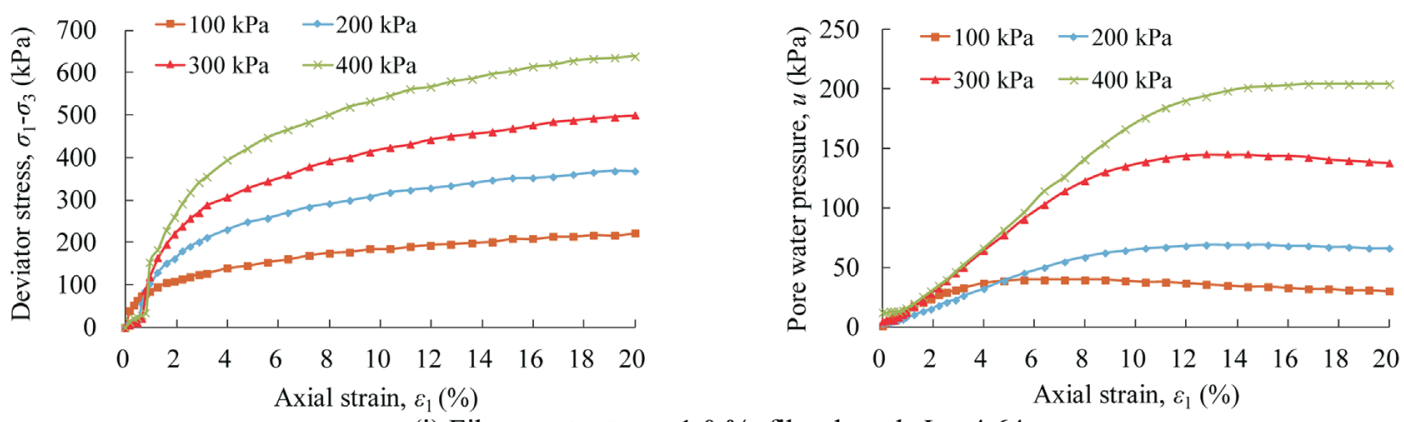

(i) Fiber content $a_{f}=1.0 \%$, fiber length $L=4.64 \mathrm{~cm}$
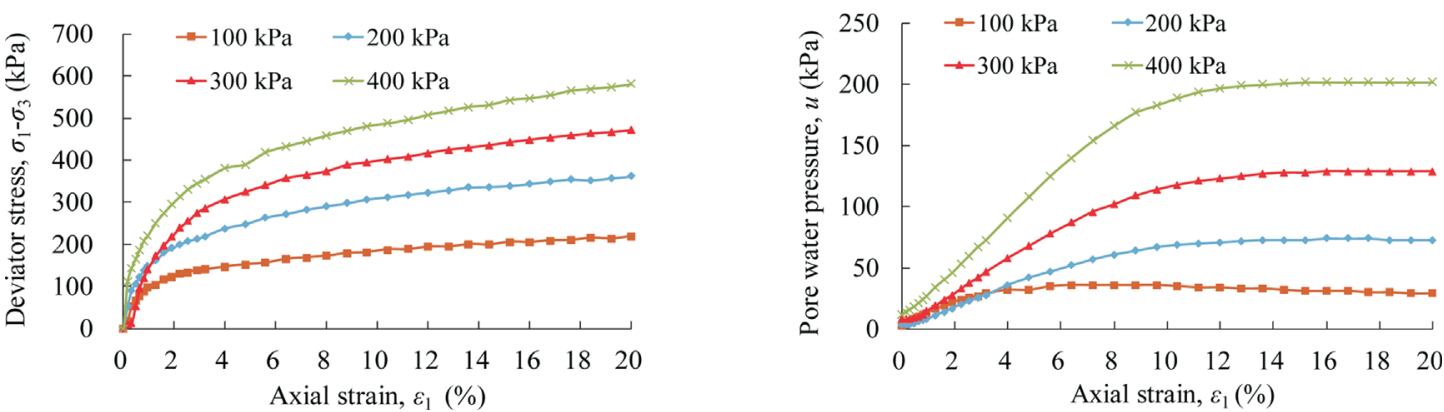

(j) Fiber content $a_{f}=1.0 \%$, fiber length $L=6.18 \mathrm{~cm}$

Figure 2 (cont.) - Stress - strain - pore water pressure relation curves.

\subsection{Effective stress path}

The effective stress of the fiber reinforced soil is assumed to be the stress shared by both the soil particles and the fibers under the external load, and is solved by the Terzaghi principle of effective stress. The effective stress paths of the fiber reinforced soil in the $p^{\prime}-q$ surface are shown in Fig. 3; the meanings of physical symbols in Fig. 3 are as follows: $p^{\prime}=p-u=\left(\sigma_{1}+\sigma_{3}\right) / 2-u ; q=\left(\sigma_{1}-\sigma_{3}\right) / 2 . \sigma_{1}$ is maximum principal stress; $\sigma_{3}$ is minimum principal stress; $K_{f}$ line is effective stress failure principal stress line. The effective stress path of the reinforced soil is a shape changing curve: it is a straight line when the strain is at the initial period, and then the curve begins to bend to the left. When the sample is near failure, the curve bends to the right and then develops along the failure principal stress line. With the increasing of fiber content, the stress path curve gradually moves to the left. When the fiber content is not more than $1.0 \%$, the effective stress path of the fiber reinforced soil is on the right side of that of the unreinforced soil. The stress path of the reinforced soil is on the left side of that of the unreinforced soil when the fiber content is more than $1.0 \%$. The main reason is that the space occupied by soil particles is replaced by fibers with the increasing of fiber content. Because the cotton fiber has loose structure, it increases the pore volume in the soil sample, resulting in the increasing of the void ratio. At the initial stage of strain, the average effective principal stress increases, the deviator stress increases, and the effect of the fiber content on the effective stress path is not obvious. With the increasing of strain, the average effective principal stress decreases significantly, and the deviator stress continues to increase. The greater the fiber content is, the more severe is the decrease of the average effective principal stress. With the further increase of strain, the average effective principal stress reaches a turning point and begins to increase, and the deviator stress increases along the failure principal stress line. The fiber length has no obvious effect on the effective stress path of fiber reinforced soil.

\subsection{Pore water pressure coefficient}

The relationship between the pore water pressure and the deviator stress $\left(\sigma_{1}-\sigma_{3}\right)$ of saturated fiber reinforced soil is shown in Fig. 4. (1) The pore water pressure increases with the increase of the deviator stress, and then eventually tends to a stable value. (2) The relationship between pore water pressure and deviator stress is nonlinear, and the curve is shown as "concave" first and then "convex".

The British scholar A.W. Skempton pointed out that the pore water pressure caused by the deviator stress is $\Delta u_{1}=A B\left(\Delta \sigma_{1}-\Delta \sigma_{3}\right)$. The pore water pressure coefficient $B$ is the coefficient related to saturation, and $B$ is approximately equal to 1 for saturated soil. The pore water pressure coefficient $A$ reflects shear dilatancy of the soil, it is not a constant but a function of the stress level in the experimental process. The pore water pressure coefficient $A=\Delta u_{1} /\left(\Delta \sigma_{1}-\Delta \sigma_{3}\right)$ can be solved through the relationship curve between the pore water pressure and the deviator stress $\left(\sigma_{1}-\sigma_{3}\right)$. As is shown in Fig. 5, in that curve, there are 


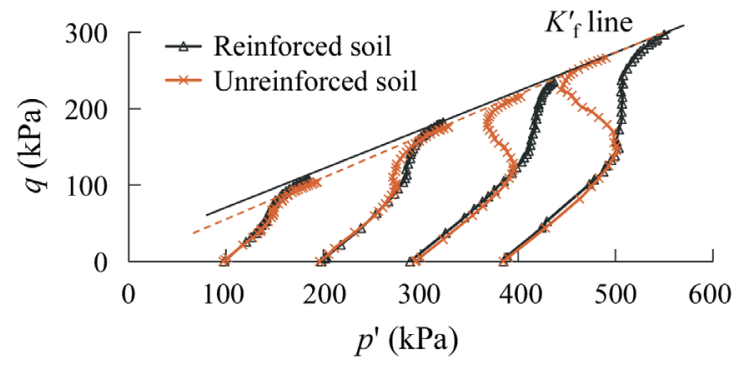

(a) Fiber length $L=3.09 \mathrm{~cm}$, fiber content $a_{f}=0.5 \%$

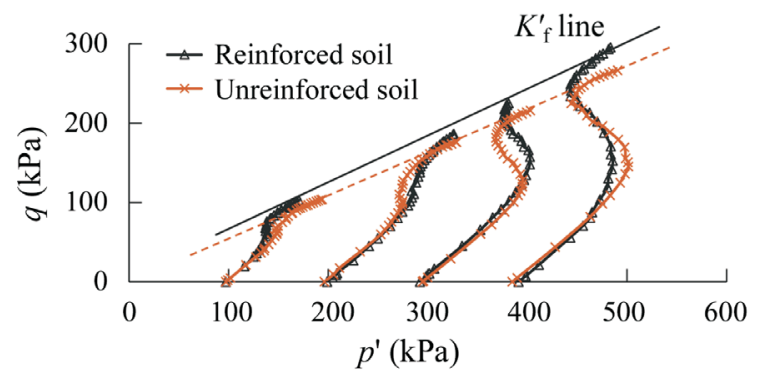

(c) Fiber length $L=3.09 \mathrm{~cm}$, fiber content $a_{f}=1.5 \%$

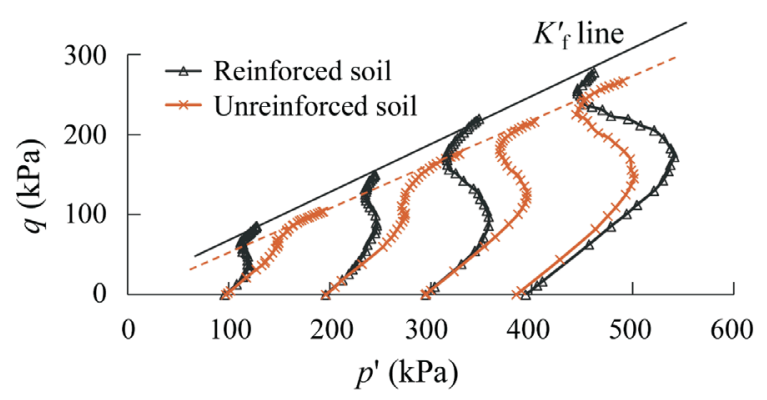

(e) Fiber length $L=3.09 \mathrm{~cm}$, fiber content $a_{f}=2.5 \%$

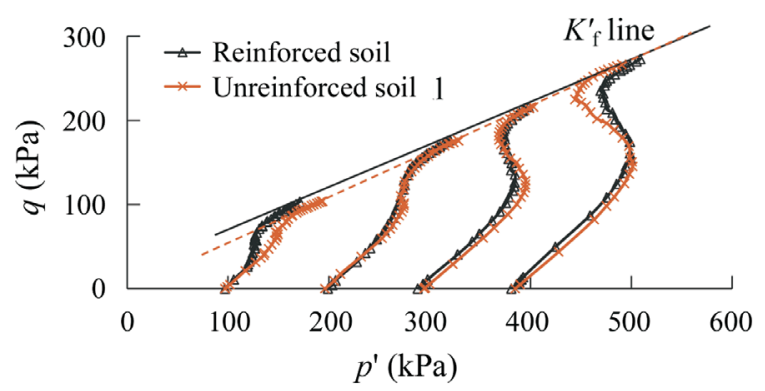

(g) Fiber content $a_{f}=1.0 \%$, fiber length $L=1.55 \mathrm{~cm}$

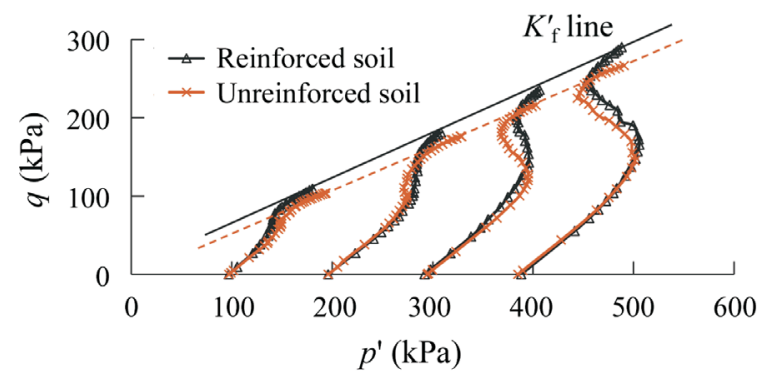

(i) Fiber content $a_{f}=1.0 \%$, fiber length $L=6.18 \mathrm{~cm}$

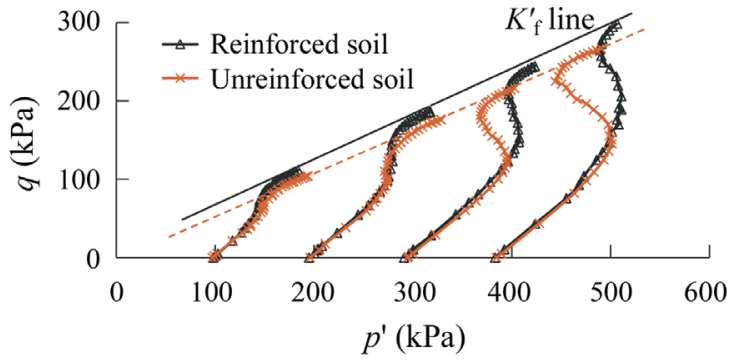

(b) Fiber length $L=3.09 \mathrm{~cm}$, fiber content $a_{f}=1.0 \%$

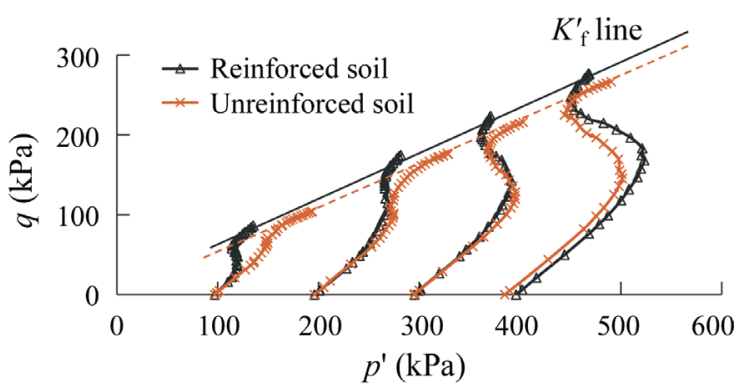

(d) Fiber length $L=3.09 \mathrm{~cm}$, fiber content $a_{f}=2.0 \%$

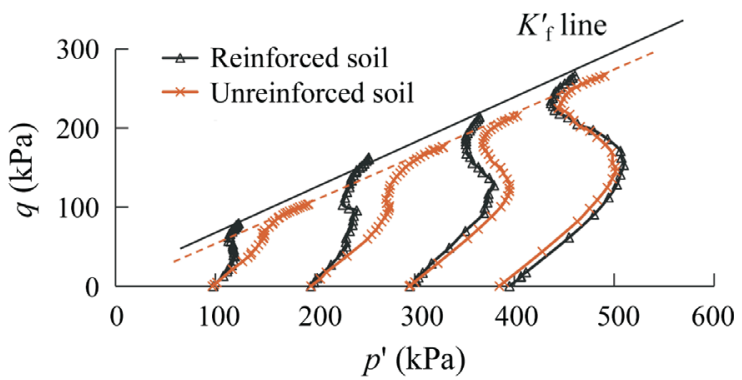

(f) Fiber length $L=3.09 \mathrm{~cm}$, fiber content $a_{f}=3.0 \%$

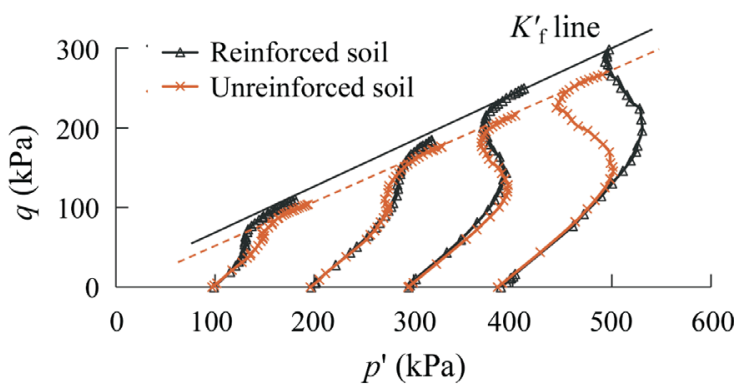

(h) Fiber content $a_{f}=1.0 \%$, fiber length $L=4.64 \mathrm{~cm}$

Figure 3 - Effective stress paths for unreinforced soil and fiber reinforced soil. 


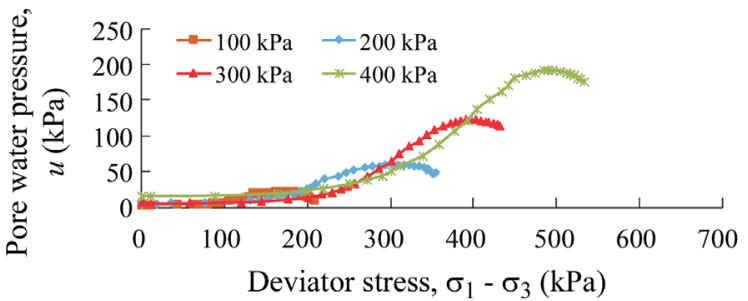

(a) Unreinforced soil

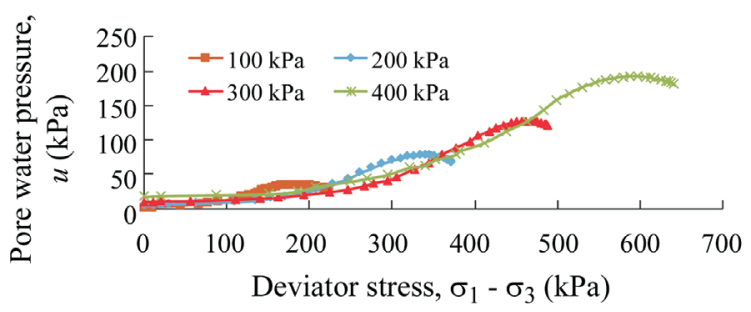

(c) Fiber length $L=3.09 \mathrm{~cm}$, fiber content $a_{f}=1.0 \%$

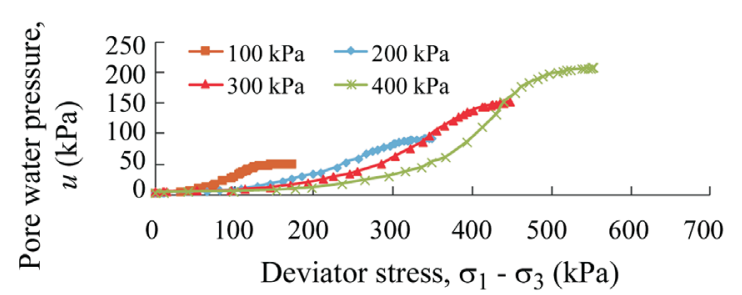

(e) Fiber length $L=3.09 \mathrm{~cm}$, fiber content $a_{f}=2.0 \%$

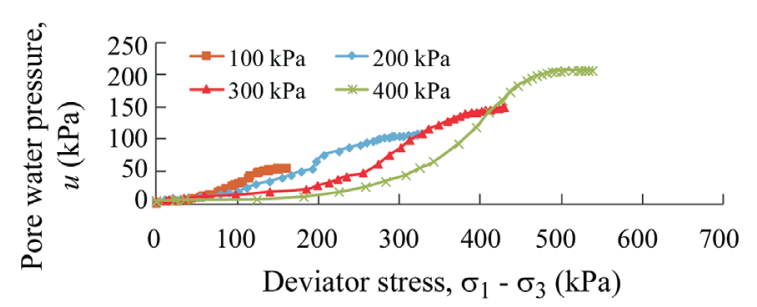

(g) Fiber length $L=3.09 \mathrm{~cm}$, fiber content $a_{f}=3.0 \%$

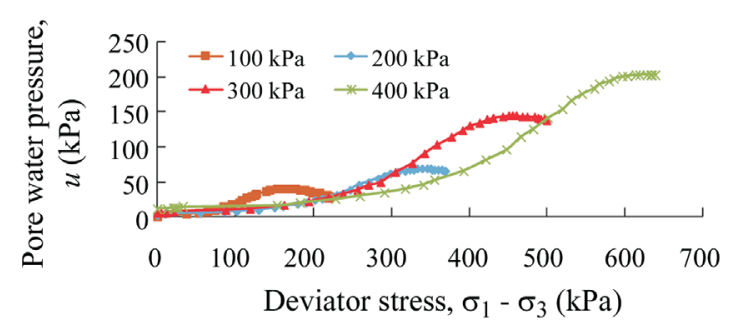

(i) Fiber content $a_{f}=1.0 \%$, fiber length $L=4.64 \mathrm{~cm}$

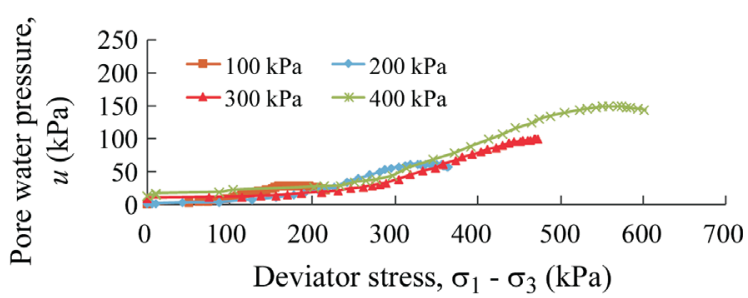

(b) Fiber length $L=3.09 \mathrm{~cm}$, fiber content $a_{f}=0.5 \%$

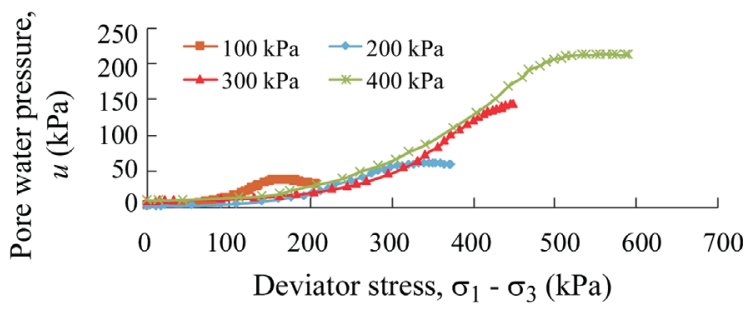

(d) Fiber length $L=3.09 \mathrm{~cm}$, fiber content $a_{f}=1.5 \%$

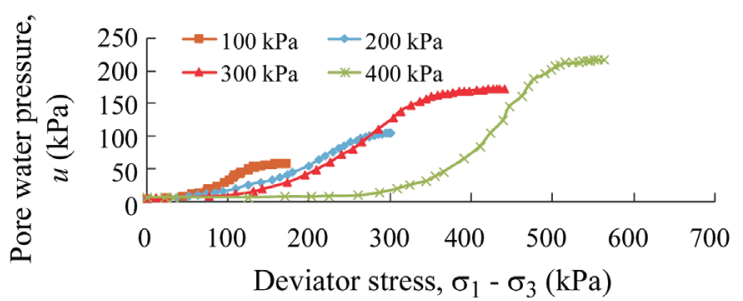

(f) Fiber length $L=3.09 \mathrm{~cm}$, fiber content $a_{f}=2.5 \%$

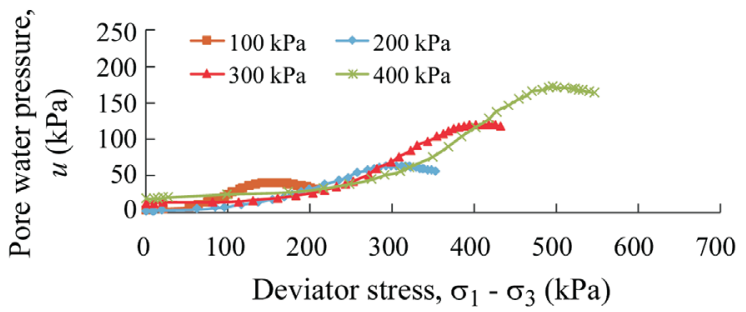

(h) Fiber content $a_{f}=1.0 \%$, fiber length $L=1.55 \mathrm{~cm}$

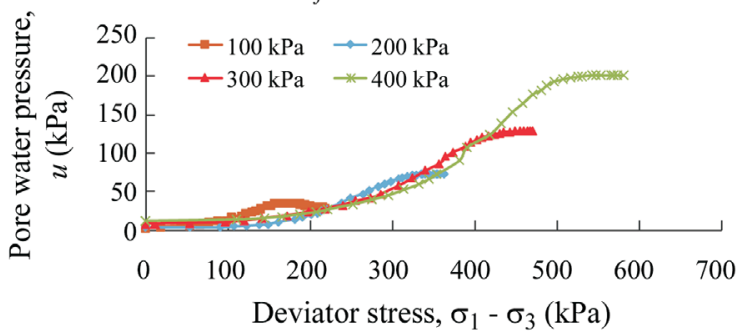

(j) Fiber content $a_{f}=1.0 \%$, fiber length $L=6.18 \mathrm{~cm}$

Figure 4 - Pore water pressure - deviator stress relation curves.

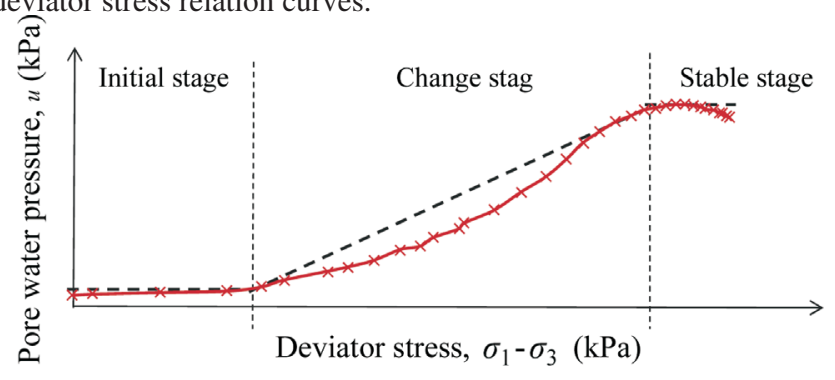

Figure 5 - A typical illustration of pore water pressure - deviator stress $\left(\sigma_{1}-\sigma_{3}\right)$ relation curves. 
three obvious stages, which are defined as initial stage, change stage and stable stage. The average pore water pressure coefficient $A_{a}$ can be solved by the secant slope of the curve during the change of stage. The average pore water pressure coefficients of the saturated compacted clay under $100 \mathrm{kPa}, 200 \mathrm{kPa}, 300 \mathrm{kPa}$, and $400 \mathrm{kPa}$ confining pressure are $0.27,0.33,0.59$ and 0.80 , respectively. The average pore water pressure coefficients of the fiber reinforced soil with $1.0 \%$ fiber content and $3.09 \mathrm{~cm}$ fiber length under $100 \mathrm{kPa}, 200 \mathrm{kPa}, 300 \mathrm{kPa}$, and $400 \mathrm{kPa}$ confining pressure are $0.35,0.43,0.45$ and 0.46 , respectively. By calculating all the fiber reinforced soil samples' parameters, the value range of pore water pressure coefficient $A$ of the compacted cotton fiber reinforced soil with $0.5 \% \sim 3.0 \%$ fiber content and $1.55 \mathrm{~cm} \sim 6.18 \mathrm{~cm}$ fiber length is $0.32 \sim 0.69$. This demonstrates that the engineering properties of compacted cotton fiber reinforced soil are similar to those of slightly overconsolidated clay.

\subsection{Shear strength parameters}

The Mohr circles and shear strength envelopes of total stress and effective stress of saturated cotton fiber reinforced soil are shown in Fig. 6. (1) The total stress strength

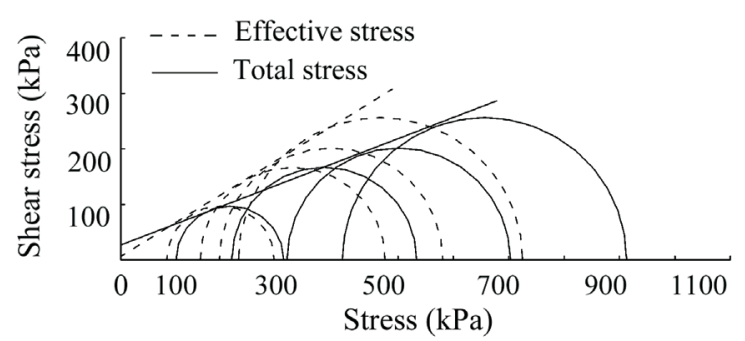

(a) Unreinforced soil

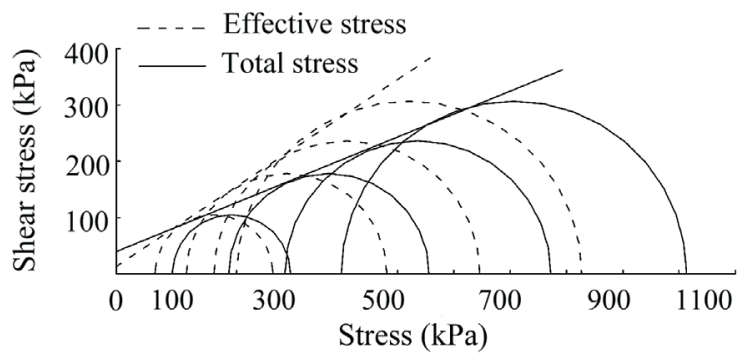

(c) Fiber length $L=3.09 \mathrm{~cm}$, fiber content $a_{f}=1.0 \%$

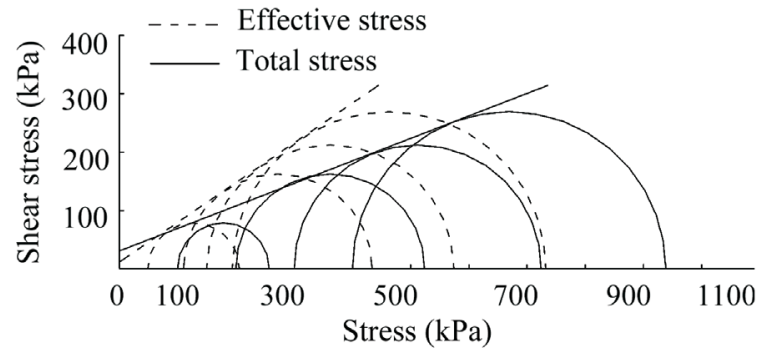

(e) Fiber length $L=3.09 \mathrm{~cm}$, fiber content $a_{f}=2.0 \%$ envelopes and effective stress strength envelopes of the fiber reinforced soil and the unreinforced soil are both a straight line approximately. The total stress strength envelopes are crossed with the effective stress strength envelopes, the effective cohesion is less than cohesion and the effective internal friction angle is larger than the internal friction angle. (2) The total stress strength envelopes of fiber reinforced soil and unreinforced soil with different reinforcement conditions are approximately parallel, and the effective stress strength envelopes are approximately parallel.

As is shown in Fig. 7, (1) The cohesion of fiber reinforced soil increases first and then decreases with the increase of fiber content, and the cohesion is the largest with $1.0 \%$ fiber content. When the fiber length of the reinforced soil is $3.09 \mathrm{~cm}$, the fiber content increases from $0.5 \%$ to $1.0 \%$, and the cohesion increases $10.1 \%$, from $36.06 \mathrm{kPa}$ to $39.71 \mathrm{kPa}$. The fiber content increases from $1.0 \%$ to $3.0 \%$, and the cohesion decreases $63.5 \%$, from $39.71 \mathrm{kPa}$ to $14.49 \mathrm{kPa}$. (2) The cohesion of fiber reinforced soil increases first and then decreases with the increase of fiber length, and the critical length or optimum length is $3.09 \mathrm{~cm}$. When the fiber length reaches the critical length, the cohe-

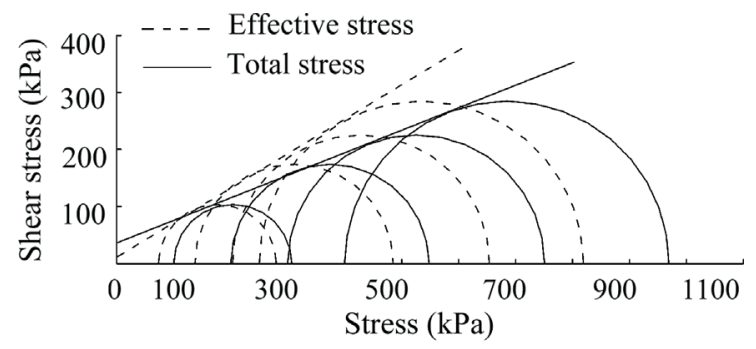

(b) Fiber length $L=3.09 \mathrm{~cm}$, fiber content $a_{f}=0.5 \%$

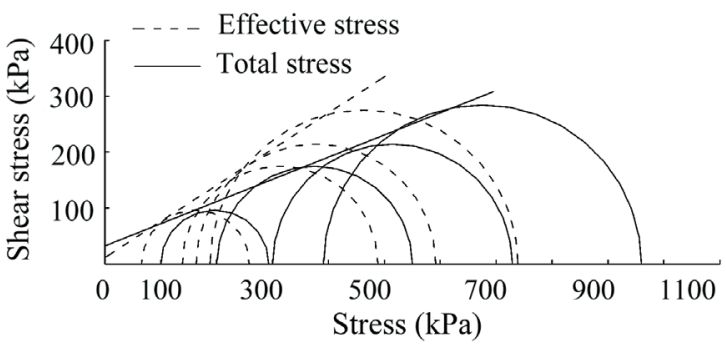

(d) Fiber length $L=3.09 \mathrm{~cm}$, fiber content $a_{f}=1.5 \%$

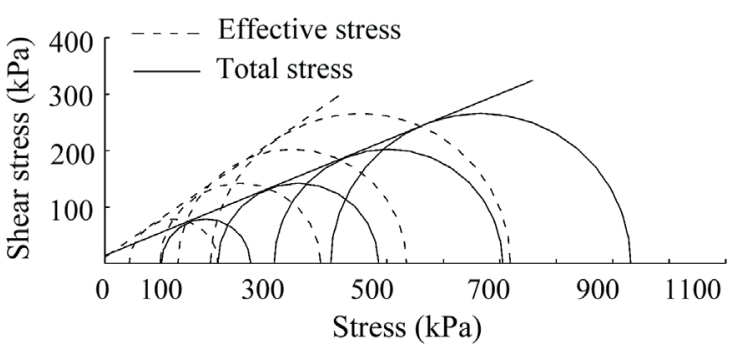

(f) Fiber length $L=3.09 \mathrm{~cm}$, fiber content $a_{f}=2.5 \%$

Figure 6 - Mohr circle and shear strength envelope of unreinforced soil and fiber reinforced soil. 


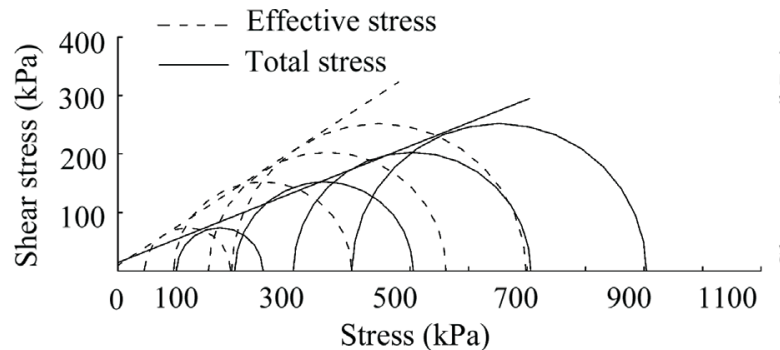

(g) Fiber length $L=3.09 \mathrm{~cm}$, fiber content $a_{f}=3.0 \%$

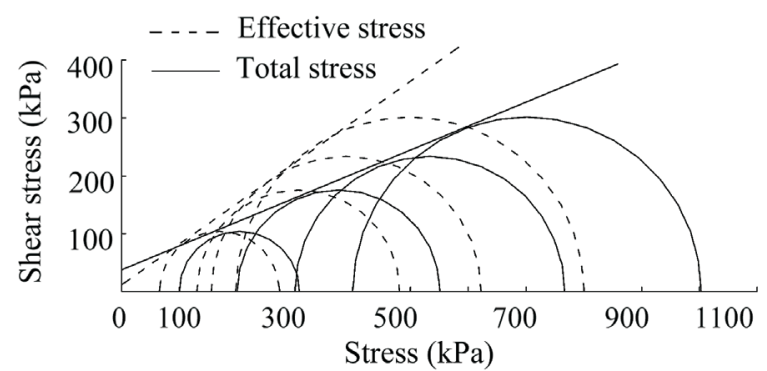

(i) Fiber content $a_{f}=1.0 \%$ fiber length $L=4.64 \mathrm{~cm}$

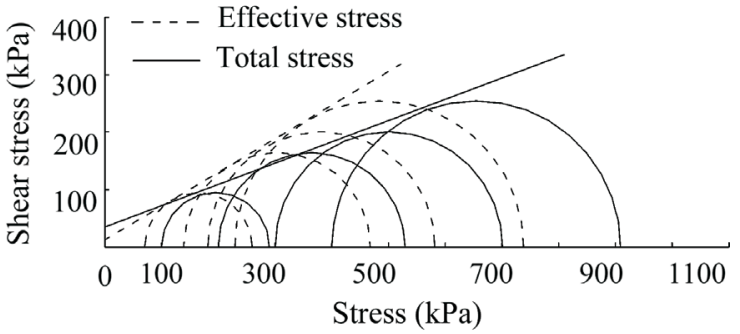

(h) Fiber content $a_{f}=1.0 \%$ fiber length $L=1.55 \mathrm{~cm}$

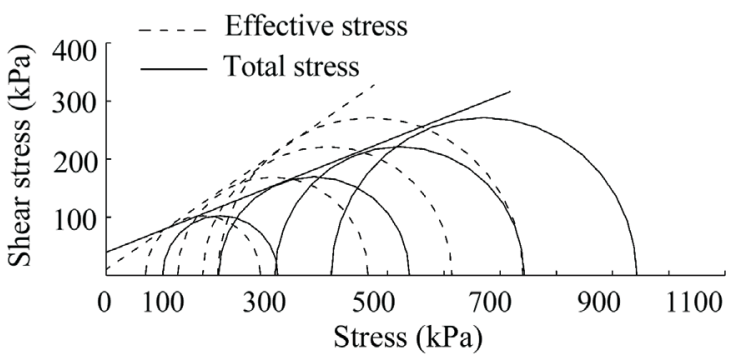

(j) Fiber content $a_{f}=1.0 \%$ fiber length $L=6.18 \mathrm{~cm}$

Figure 6 (cont.) - Mohr circle and shear strength envelope of unreinforced soil and fiber reinforced soil.

sion decreases with the increase of the fiber length, but the effect is not obvious. As for $1.0 \%$ fiber content of fiber reinforced soil, the fiber length increases from $1.55 \mathrm{~cm}$ to $3.09 \mathrm{~cm}$, and the cohesion increases $12.9 \%$, from $35.17 \mathrm{kPa}$ to $39.71 \mathrm{kPa}$. The fiber length increases from $3.09 \mathrm{~cm}$ to $6.18 \mathrm{~cm}$, and the cohesion decreases $0.9 \%$, from $39.71 \mathrm{kPa}$ to $39.37 \mathrm{kPa}$. (3) The cohesion and effective cohesion of fiber reinforced soil with $3.09 \mathrm{~cm}$ fiber length and $1.0 \%$ fiber content increase by $48.4 \%$ and $112.3 \%$, respectively, compared with unreinforced soil.

As is shown in Fig. 8, the internal friction angle and the effective internal friction angle of the unreinforced soil are $20.96^{\circ}$ and $31.53^{\circ}$ respectively, the internal friction angle range of the reinforced soil with $3.09 \mathrm{~cm}$ fiber length and $0.5 \% \sim 3.0 \%$ fiber content is $21.10^{\circ} \sim 22.24^{\circ}$, and the effective internal friction angle range is $31.16^{\circ} \sim 34.54^{\circ}$. The internal friction angle range of the reinforced soil with

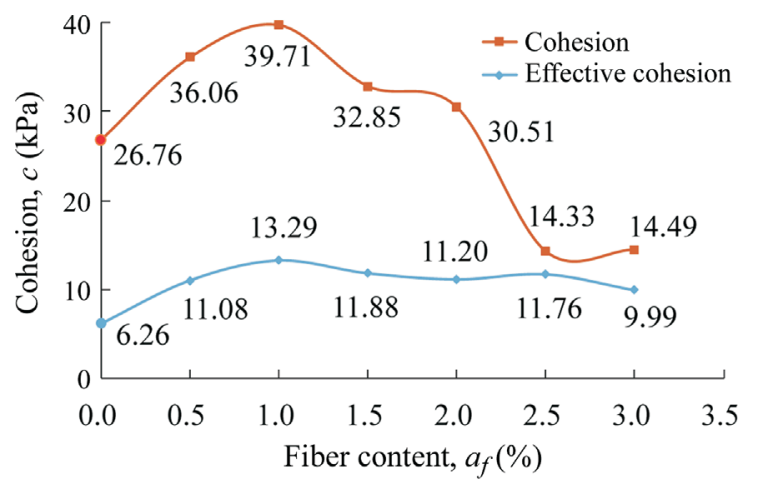

(a) Cohesion - fiber content relation curves (fiber lenght $L=3.09 \mathrm{~cm}$ )
$1.0 \%$ fiber content and $1.55 \mathrm{~cm} \sim 6.18 \mathrm{~cm}$ fiber length is $20.31^{\circ} \sim 22.51^{\circ}$, and the effective internal friction angle range is $30.38^{\circ} \sim 35.16^{\circ}$. The internal friction angle of the fiber reinforced soil is basically the same as that of the unreinforced soil, and the reinforcement condition has no significant effect on the internal friction angle of the fiber reinforced soil.

The optimal fiber content is $1.0 \%$, and the optimum fiber length is $3.09 \mathrm{~cm}$ based on the analysis of the test results. According to the random distribution patterns of fibers in the samples by observation, summing up the existence form of flexible fibers in samples, the interaction modes between fibers and soil consists of three kinds: (1) Contact. The contact action between the fibers and soil particles provides the interfacial shear stress between the fibers and soil particles. (2) Bending. The fibers are bent in the soil, the soil particles are wrapped by fibers at the bend,

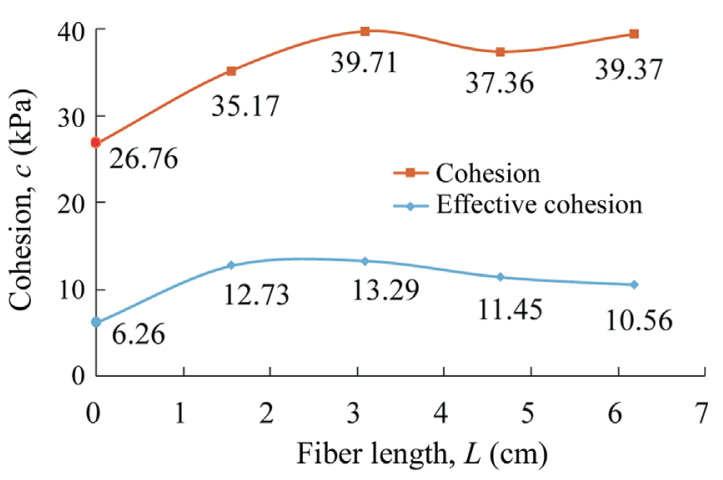

(b) Cohesion - fiber length relation curves (fiber content $a_{f}=1.0 \%$ )

Figure 7 - Cohesion - fiber content, fiber length relation curves of fiber reinforced soil. 


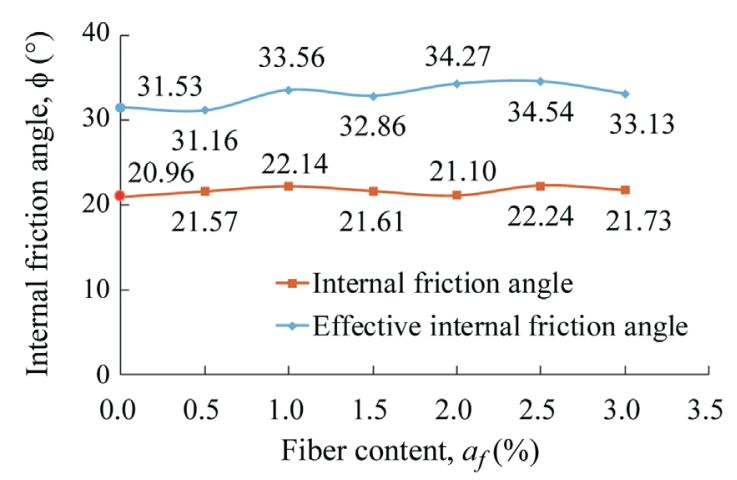

(a) Internal friction angle - fiber content relation curves (fiber lenght $L=3.09 \mathrm{~cm}$ )

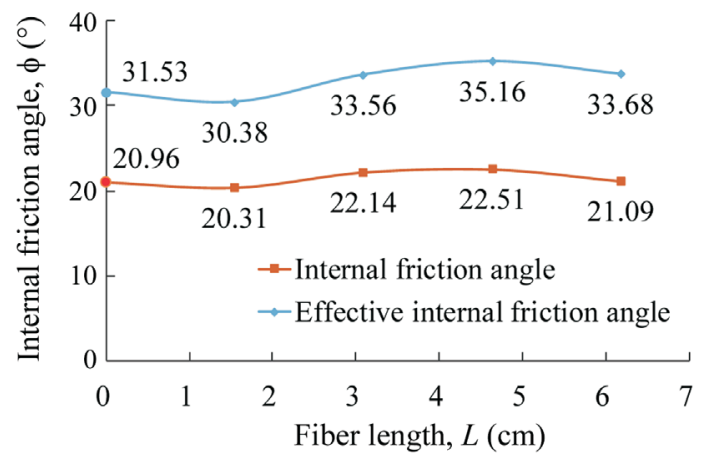

(b) Internal friction angle - fiber length relation curves (fiber content $a_{f}=1.0 \%$ )

Figure 8 - Internal friction angle - fiber content, fiber length relation curves of fiber reinforced soil.

and tensile stress appears in the fibers because of the movement or movement tendency of soil particles under external load. (3) Interweaving. The fibers are a kind of network structure in the soil, and the three-dimensional network of the fibers can effectively restrict the movement of the soil particles. The movement difficulty of soil particles during the loading process of saturated soil has an important influence on the strength of soil. The results of the interaction between the fibers and soil particles can effectively restrict the movement of soil particles, thus the strength of the soil can be improved. The effect of the fiber content and the fiber length on fiber reinforced soil can be well explained by the interaction between the fibers and the soil particles (Liu et al., 2018; Oliveira et al., 2019; Xie et al., 2019).

As to fiber content, the total contact area between the fibers and soil particles is limited when the fiber content is too low, and the fibers cannot be interwoven into the net, thus the increase of soil strength is limited. When the fiber content is too high, the fibers are stacked, thus the fibers and the soil particles cannot be in full contact. If the fibers are still in the "floating" state, the fibers are not anchored by the soil, or the anchorage is not enough, and the tensile property of the fibers cannot be fully used. As to fiber length, the contact area between the fibers and soil is small when the fibers are too short. The fibers are easily pulled out under load, the fibers cannot be effectively bent in the soil, and the fibers cannot be interwoven into a threedimensional network. On one hand, when the fibers are too long, the fibers will be entangled with each other and they are not in full contact with the soil skeleton. On the other hand, the fiber length is too large, and a certain strain should be used to "wake up" the fibers in the soil. The strain of the specimens is not enough to induce the contribution of the fibers, which is one of the reasons for the decrease of the reinforcement effect.

In the laboratory tests, the influence of fiber length on the strength of the samples is related to the size of the samples. The unconfined compression tests of the cotton fiber reinforced soil with $100 \mathrm{~mm}$ height and $50 \mathrm{~mm}$ diameter were conducted, and the strength is the best with $1.0 \%$ fiber content and $2.5 \mathrm{~cm}$ fiber length. The unconsolidated undrained triaxial tests (UU) of the cotton fiber reinforced soil with $125 \mathrm{~mm}$ height and $61.8 \mathrm{~mm}$ diameter were carried out, and the strength is best with $1.0 \%$ fiber content and $3.09 \mathrm{~cm}$ fiber length. It can be seen that the results of unconfined compression tests, UU tests and CU tests are completely consistent, which means the optimum fiber length measured in the laboratory is $D / 2$ ( $D$ is the specimen diameter). Therefore, the optimal fiber content and the optimum fiber length determined through the laboratory tests were $1.0 \%$ and $D / 2$, respectively.

\subsection{Analysis of failure mode}

The failure mode of the samples under different reinforcement conditions is shown in Fig. 9. (1) The failure mode of saturated cotton fiber reinforced soil is bulging failure. (2) The failure mode of the unreinforced soil samples is drum shaped, which is small at both ends, large in the middle, and the end effect is obvious. The radial deformation difference between the end and the middle of the fiber reinforced soil samples is reduced, and the end effect is weakened. The fiber reinforcement can restrain the movement of soil particles. The failure mode of the samples show that the fiber reinforcement can effectively restrain the radial deformation of the samples and improve the strength of the soil.

\section{Conclusions}

(1) The stress-strain relationship of the saturated cotton fiber reinforced soil is strain hardening. The change laws of the pore water pressure with the increasing of the axial strain are affected by confining pressure and void ratio.

(2) The fiber length has no obvious effect on the effective stress path of fiber reinforced soil. With the increase of fiber content, the effective stress path in $p^{\prime}-q$ surface of the reinforced soil gradually moves to the left side 


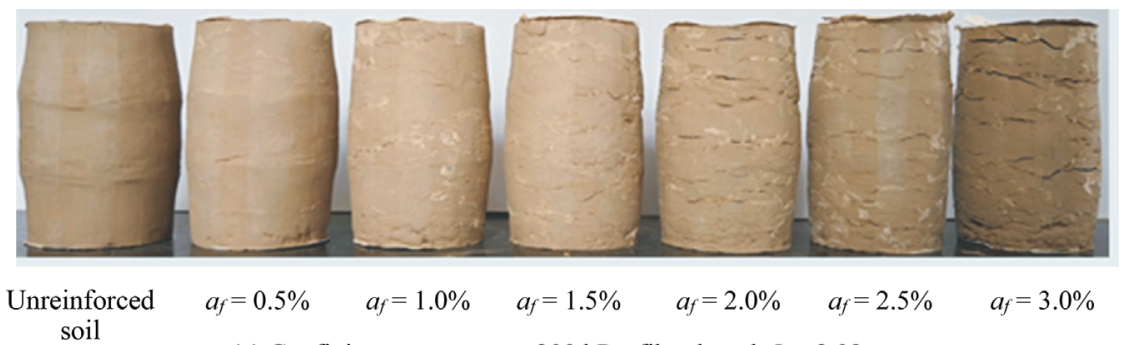

(a) Confining pressure $\sigma_{3}=300 \mathrm{kPa}$, fiber length $L=3.09 \mathrm{~cm}$

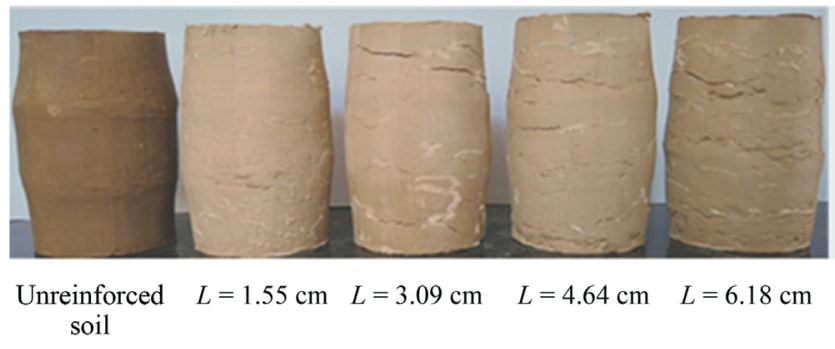

(b) Confining pressure $\sigma_{3}=200 \mathrm{kPa}$, fiber content $a_{f}=1.0 \%$

Figure 9 - Failure mode of fiber reinforced soil samples.

from the right side of that of unreinforced soil. The critical value of fiber content is $1.0 \%$.

(3) The relationship between pore water pressure and deviator stress is nonlinear, and it consists of three evident stages: initial stage, change stage and stable stage. The engineering properties of compacted cotton fiber reinforced soil are similar to those of slightly overconsolidated clay.

(4) There is an optimal fiber content and an optimum fiber length which are $1.0 \%$ and $3.09 \mathrm{~cm}$, respectively. Under the optimal fiber reinforced conditions, the effective cohesion of the fiber reinforced soil increases by $112.3 \%$ compared with unreinforced soil. The internal friction angle of fiber reinforced soil is basically the same as that of the unreinforced soil, and the reinforcement condition has no significant effect on the internal friction angle of fiber reinforced soil.

(5) There are three fiber existing forms in fiber reinforced soil: contact, bending and interweaving. The failure mode of saturated cotton fiber reinforced soil is bulging failure. The reinforcement effect can effectively restrain the radial deformation of the samples.

\section{References}

Anagnostopoulos, C.A.; Papaliangas, T.T.; Konstantinidis, D. \& Patronis, C. (2013). Shear strength of sands reinforced with polypropylene fibers. Geotechnical and Geological Engineering, 31(2):401-423.

Chaduvul, U.; Viswanadham, B.V.S. \& Kodikara, J. (2017). A study on desiccation cracking behavior of polyester fiber-reinforced expansive clay. Applied Clay Science, 142(2):163-172.
Chai, S.X. \& Shi, Q. (2012). Strength and deformation of saline soil reinforced with rice straw. Journal of PLA University of Science and Technology (Natural Science Edition), 13(6):646-650.

Correia, A.A.S.; Venda Oliveira, P.J. \& Custódio, D.G. (2015). Effect of polypropylene fibres on the compressive and tensile strength of a soft soil, artificially stabilised with binders. Geotexiles and Geomembranes, 43(2):97-106.

Diab, A.A.; Sadek, S.; Najjar, S. \& Daya, M.H.A. (2016). Undrained shear strength characteristics of compacted clay reinforced with natural hemp fibers. International Journal of Geotechnical Engineering, 10(3):263-270.

Diambra, A.; Ibraim E.; Russell, A.R. \& Muir Wood, D. (2013). Fibre reinforced sands: from experiments to modelling and beyond. International Journal for $\mathrm{Nu}-$ merical and Analytical Methods in Geomechanics, 37(15):2427-2455.

Diambra, A. \& Ibraim, E. (2015). Fibre-reinforced sand: Interaction at the fibre and grain scale. Géotechnique, 65(4):296-308.

Estabragh, A.R.; Bordbar, A.T. \& Javadi, A.A. (2011). Mechanical behavior of a clay soil reinforced with nylon fibers. Geotechnical and Geological Engineering, 29(5):899-908.

Hou, T.S. (2012). Influence of expanded polystyrene size on deformation characteristics of light weight soil. Journal of Central South University, 19(11):3320-3328.

Hou, T.S. (2014). Model for compaction density and engineering properties of light weight soil. Chinese Journal of Geotechnical Engineering, 36(11):2127-2135.

Hou, T.S. \& Xu, G.L. (2009). Experiment on triaxial pore water pressure-stress-strain characteristics of foamed 
particle light weight soil. China Journal of Highway and Transport, 22(6):10-17.

Hou, T.S. \& Xu, G.L. (2010). Experimental study on the shear strength characteristics of foamed particle light weight soil. Journal of China University of Mining \& Technology, 39(4):534-540.

Hou, T.S. \& Xu, G.L. (2011). Optimum water content models and tests of light weight soil. Chinese Journal of Geotechnical Engineering, 33(7):1129-1134.

Ibraim, E.; Diambra, A.; Russell, A.R. \& Muir Wood, D. (2012). Assessment of laboratory sample preparation for fibre reinforced sands. Geotextiles and Geomembranes, 34(3):69-79.

Krishna Rao, S.V. \& Nasr, A.M.A. (2012). Laboratory study on the relative performance of silty-sand soils reinforced with linen fiber. Geotechnical and Geological Engineering, 30(1):63-74.

Liu, J.L.; Hou, T.S. \& Luo, Y.S. (2018). Unconfined compressive strength of synthetic cotton fiber reinforced soil. Journal of Hydroelectric Engineering, 37(2):1221.

Michalowski, R.L. (2008). Limit analysis with anisotropic fibre-reinforced soil. Géotechnique, 58(6):489-501.

Oliveira Júnior, A.I.; Jucá, J.F.T.; Ferreira, J.A. \& Guilherme, L.C. (2019). Geotechnical behavior and soilfiber interaction of clayey soil mixed with randomly dispersed coconut fibers. Soils and Rocks, 42(2):127138.

Prabakar, J. \& Sridhar, R.S. (2002). Effect of random inclusion of sisal fibre on strength behavior of soil. Construction and Building Materials, 16(2):123-131.

Shao, W.; Cetin, B.; Li, Y.D.; Li, J.P. \& Li, L. (2014). Experimental investigation of mechanical properties of sands reinforced with discrete randomly distributed fi- ber. Geotechnical and Geological Engineering, 32(4):901-910.

Soltani, A.; Deng, A. \& Taheri, A. (2018). Swell-compression characteristics of a fiber-reinforced expansive soil. Geotextiles and Geomembranes, 46(2):183-189.

Tang, C.S.; Shi, B.; Gao, W. \& Liu, J. (2009). Single fiber pull-out test and the determination of critical fiber reinforcement length for fiber reinforced soil. Rock and Soil Mechanics, 30(8):2225-2230.

Tang, C.S.; Li, J.; Wang, D.Y. \& Shi, B. (2016a). Investigation on the interfacial mechanical behavior of waveshaped fiber reinforced soil by pullout test. Geotextiles and Geomembranes, 44(6):872-883.

Tang, C.S.; Wang, D.Y.; Cui, Y.J.; Shi, B. \& Li, J. (2016b). Tensile strength of fiber-reinforced soil. Journal of Materials in Civil Engineering, 28(7):1-13.

Wang, Y.Z.; Liu, X.F.; Zhang, Z.K.; Ma, D.G. \& Cui, Y.Q. (2015). Experimental research on influence of root content on strength of undisturbed and remolded grassroots-reinforced soil. Chinese Journal of Geotechnical Engineering, 37(8):1405-1410.

Wei, L.; Chai, S.X.; Cai, H.Z. \& Li, M. (2012). Triaxial shear strength and deviatoric stress-strain of saline soils reinforced with wheat straws. China Civil Engineering Journal, 45(1):109-114.

Xie, J.; Tang, C.S.; Yin, L.Y.; Lv, C. \& Shi, B. (2019). Mechanical behavior of microbial-induced calcite precipitation (MICP)-treated soil with fiber reinforced. Chinese Journal of Geotechnical Engineering, 41(4):675-682.

Zaimoglu, A.S. (2010). Freezing-thawing behavior of fine-grained soils reinforced with polypropylene fibers. Cold Regions Science and Technology, 60(1):63-65.

Zhang, Y.M.; Zhang, X.D. \& Zhang, H.R. (2005). Test research of geotechnique textile soil reinforcement mechanism and engineering application. Rock and Soil Mechanics, 26(8):1323-1326. 